\title{
ANALYTICAL SOLUTIONS FOR COSMOLOGICAL PERTURBATIONS WITH RELATIVISTIC COLLISIONLESS MATTER
}

\author{
ANTON REBHAN
}

Theory Division, CERN

CH-1211 Geneva 23, Switzerland

\begin{abstract}
Thermal field theory is used for the derivation of self-consistent and automatically gauge-invariant equations for cosmological perturbations. Exact, analytical solutions are obtained for scalar, vector, and tensor perturbations in the general case of a two-component system containing a perfect radiation fluid and relativistic collisionless matter. The results for scalar (energy density) perturbations agree with previous numerical integrations of the Einstein-Boltzmann equations, whereas new results are found for the vector and tensor sector. Particularly interesting are the solutions for vector perturbations on superhorizon scales, where a growing mode corresponding to spontaneous generation of vorticity in the collisionless component is found.
\end{abstract}

CERN-TH.6164/91

July 1991 


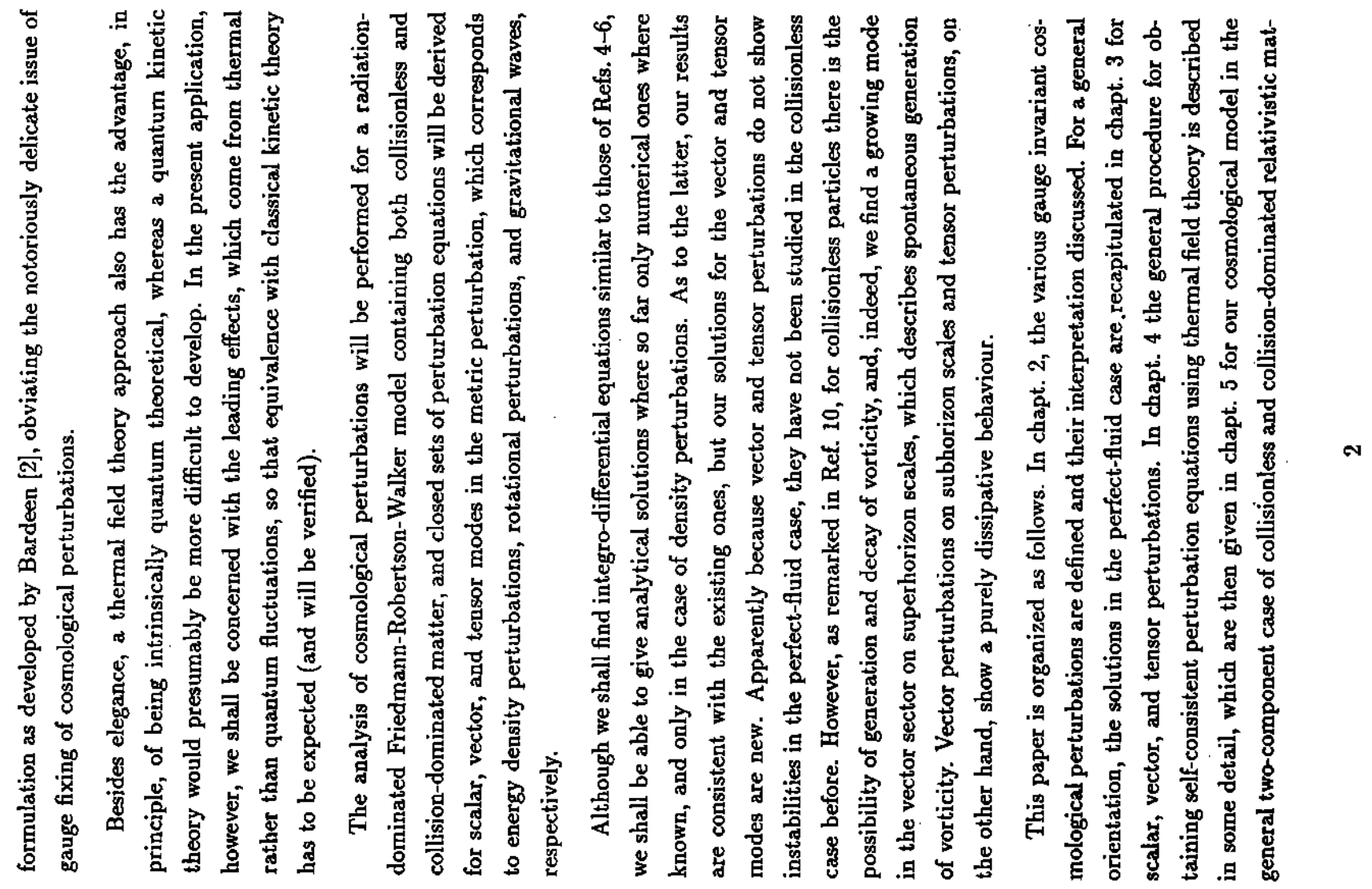

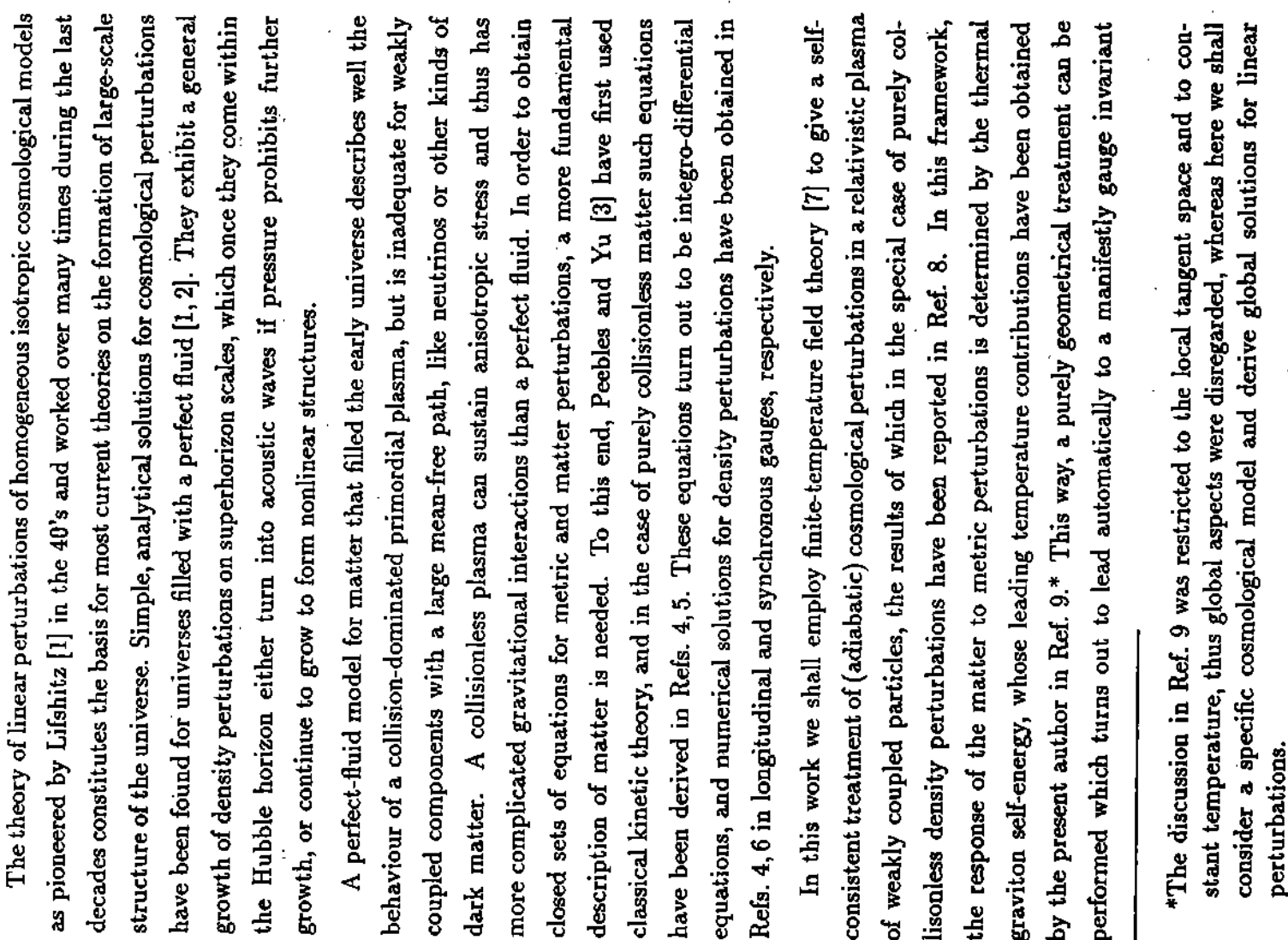



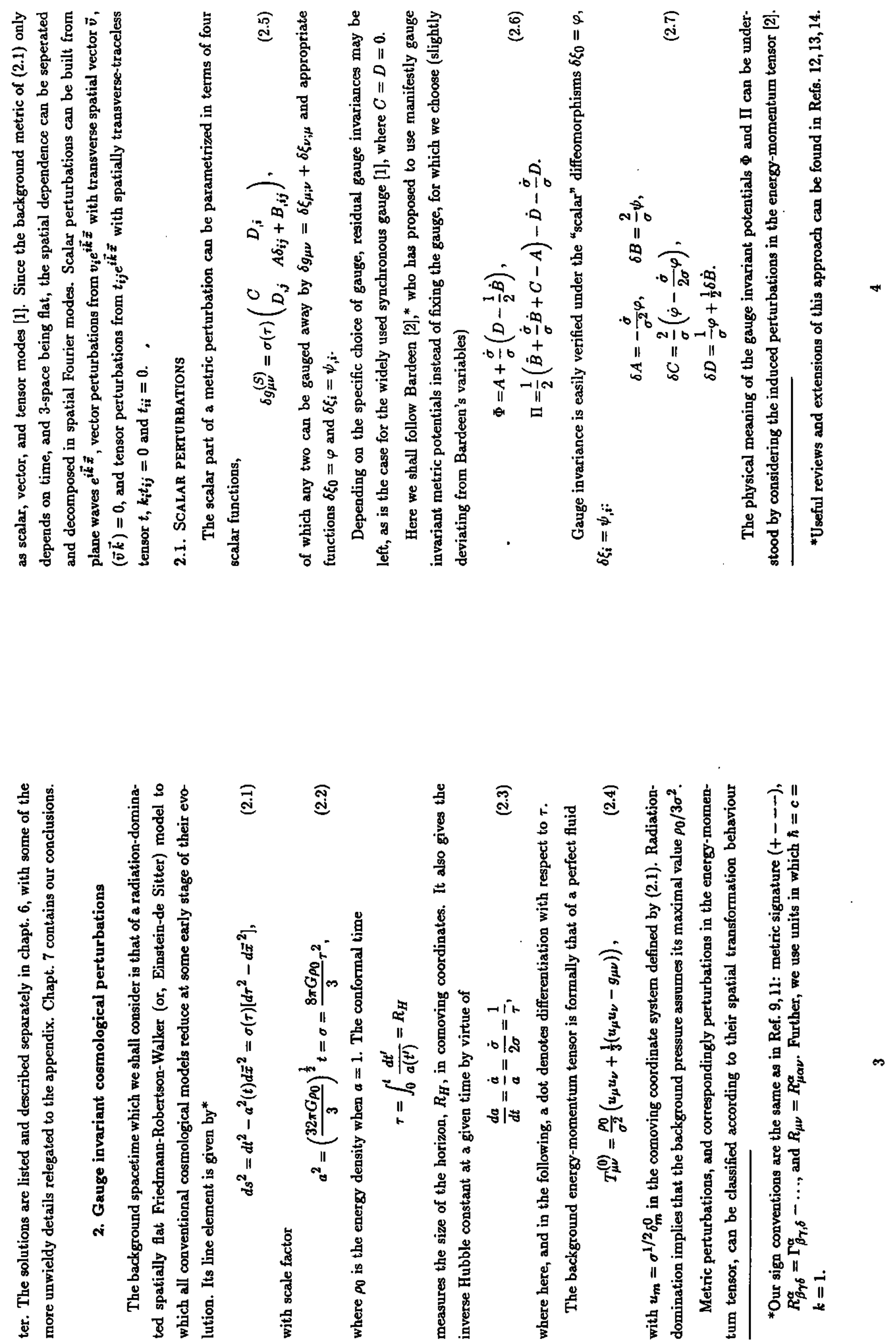

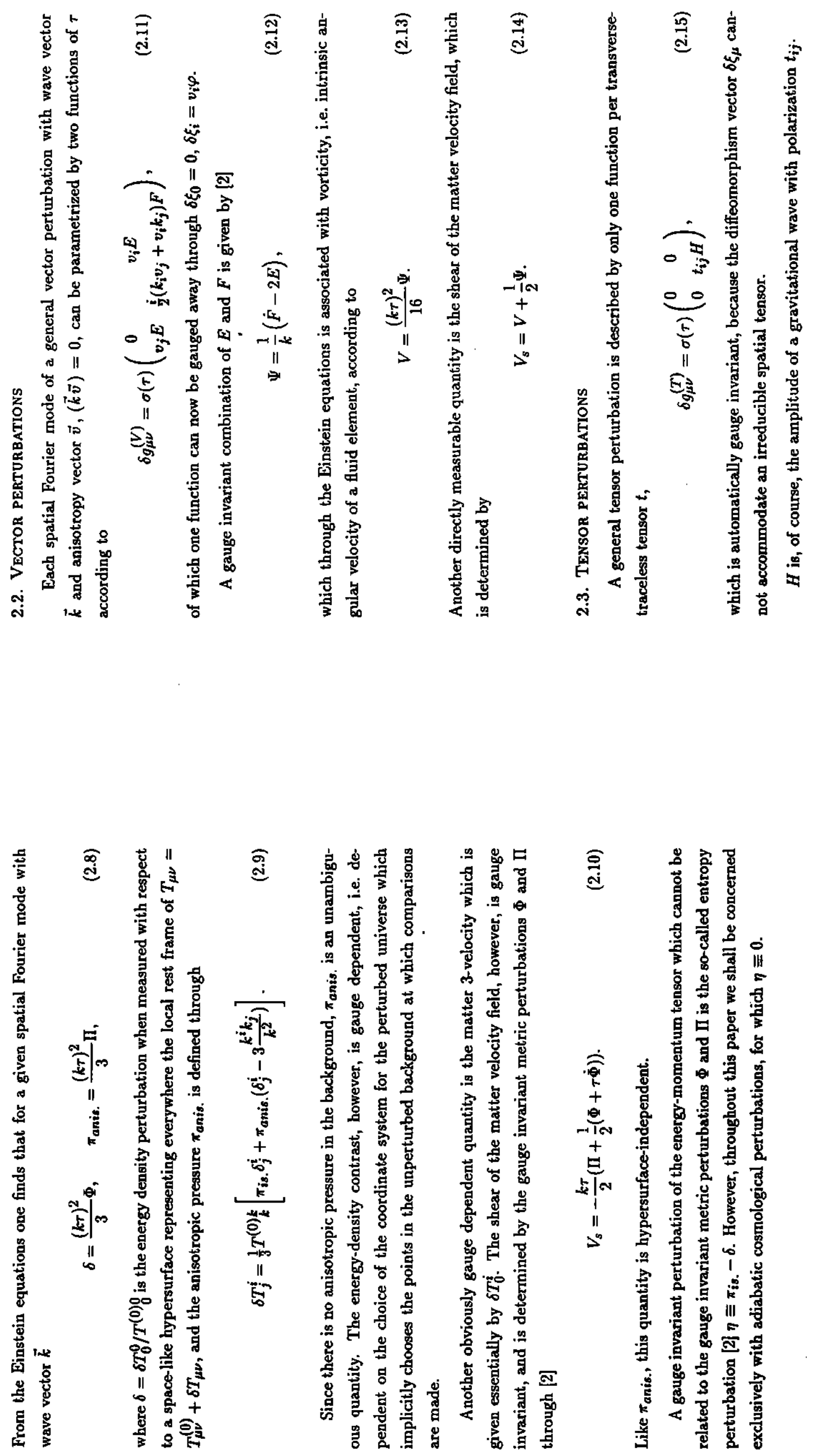

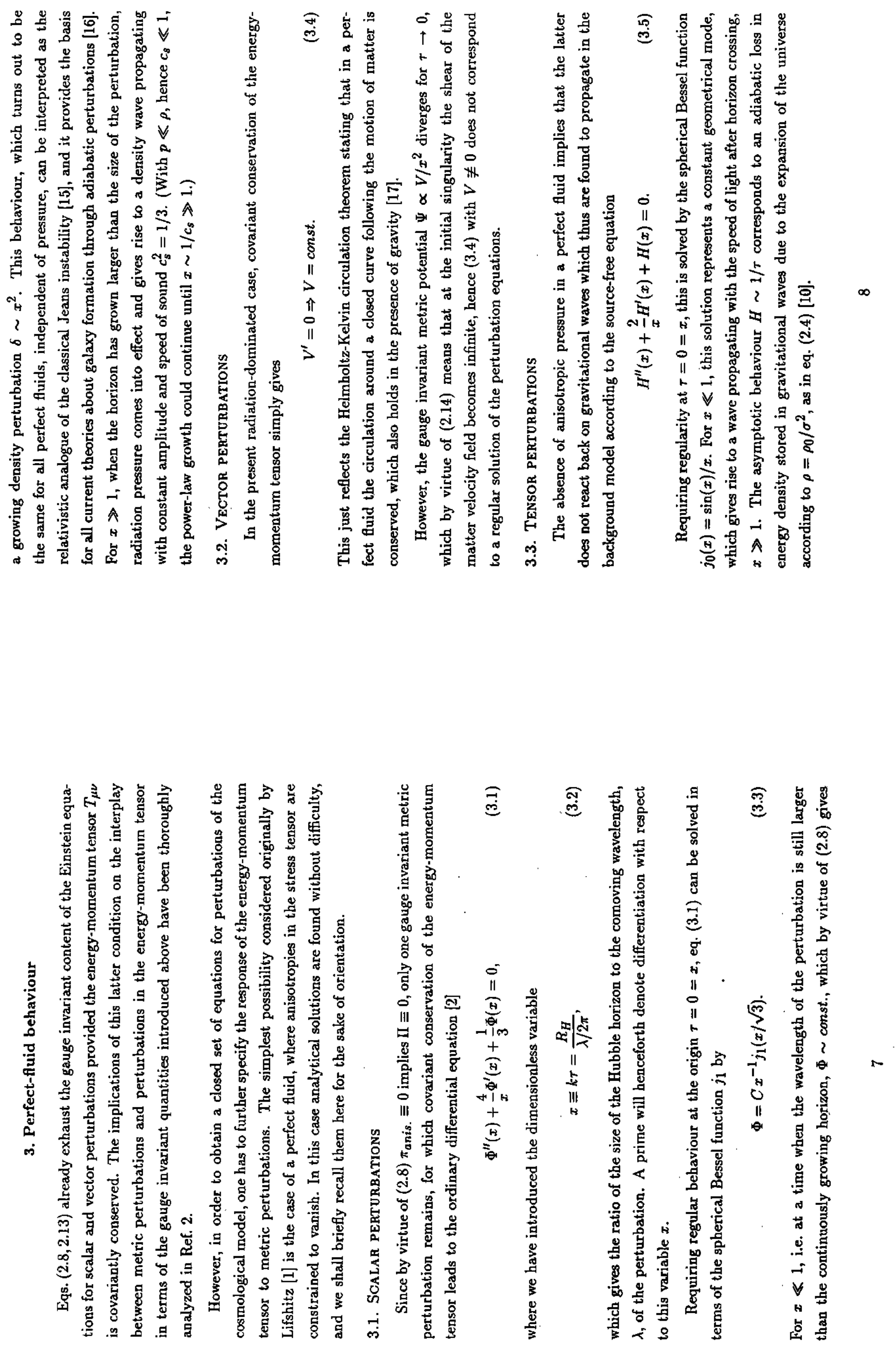

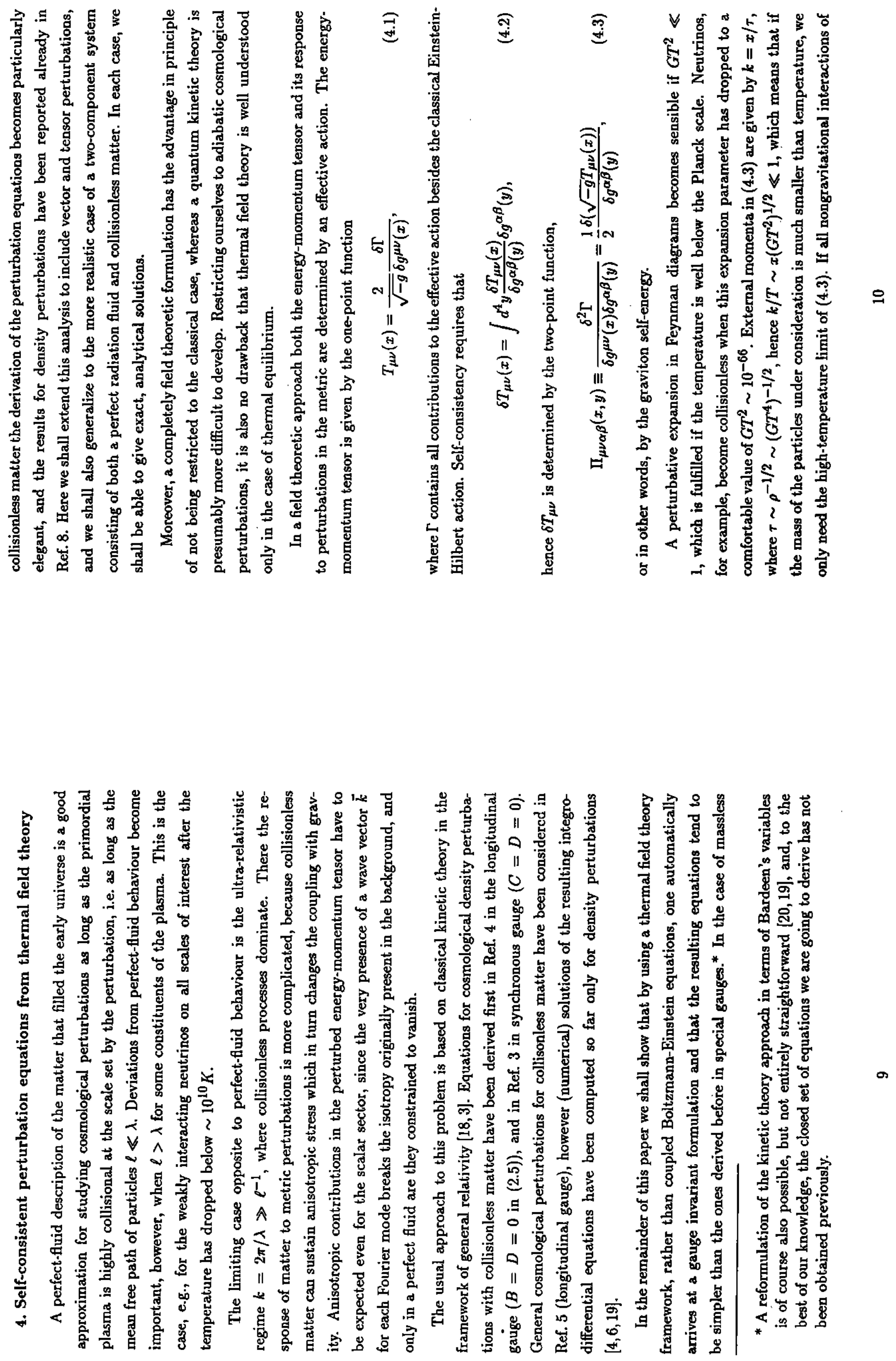

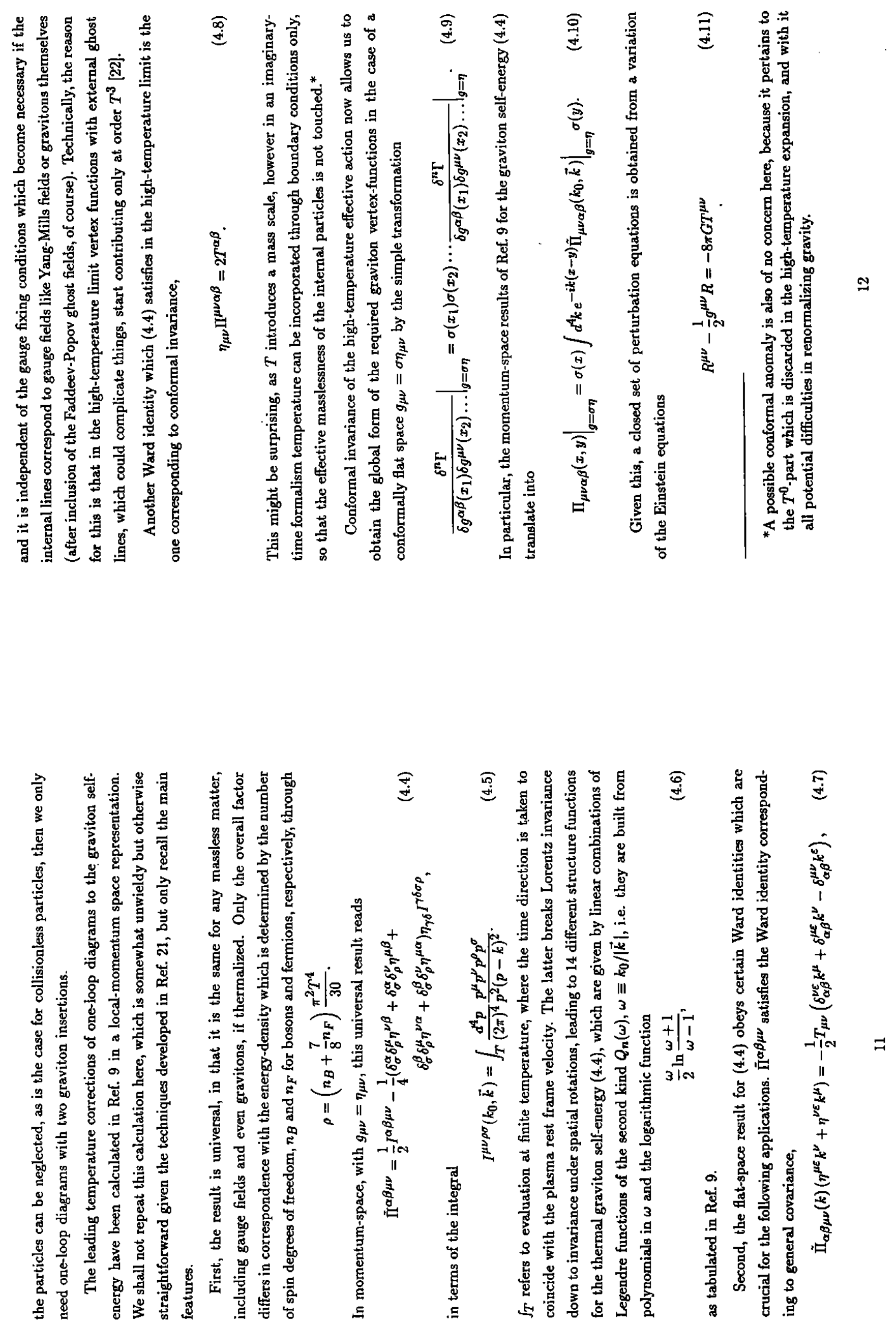

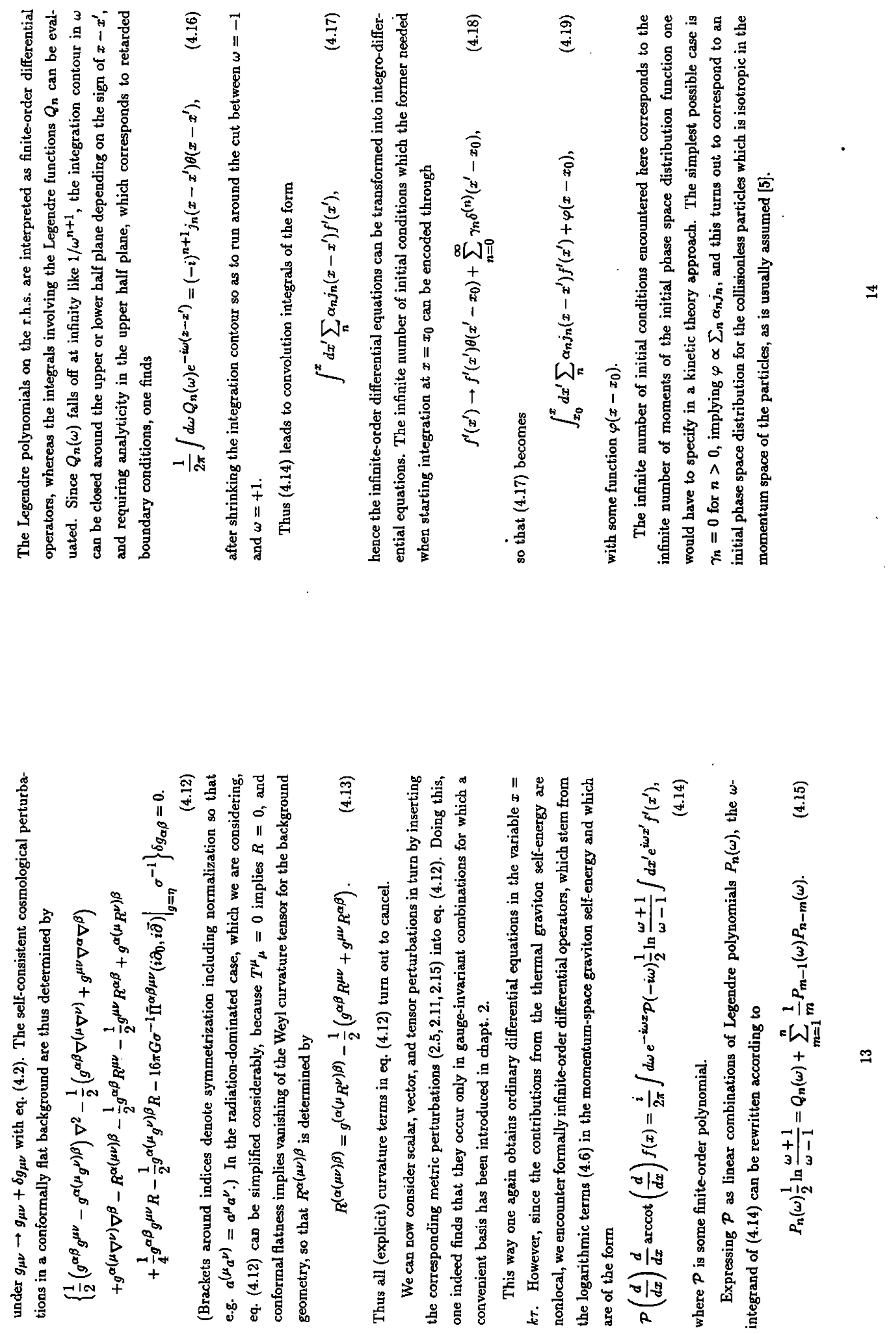


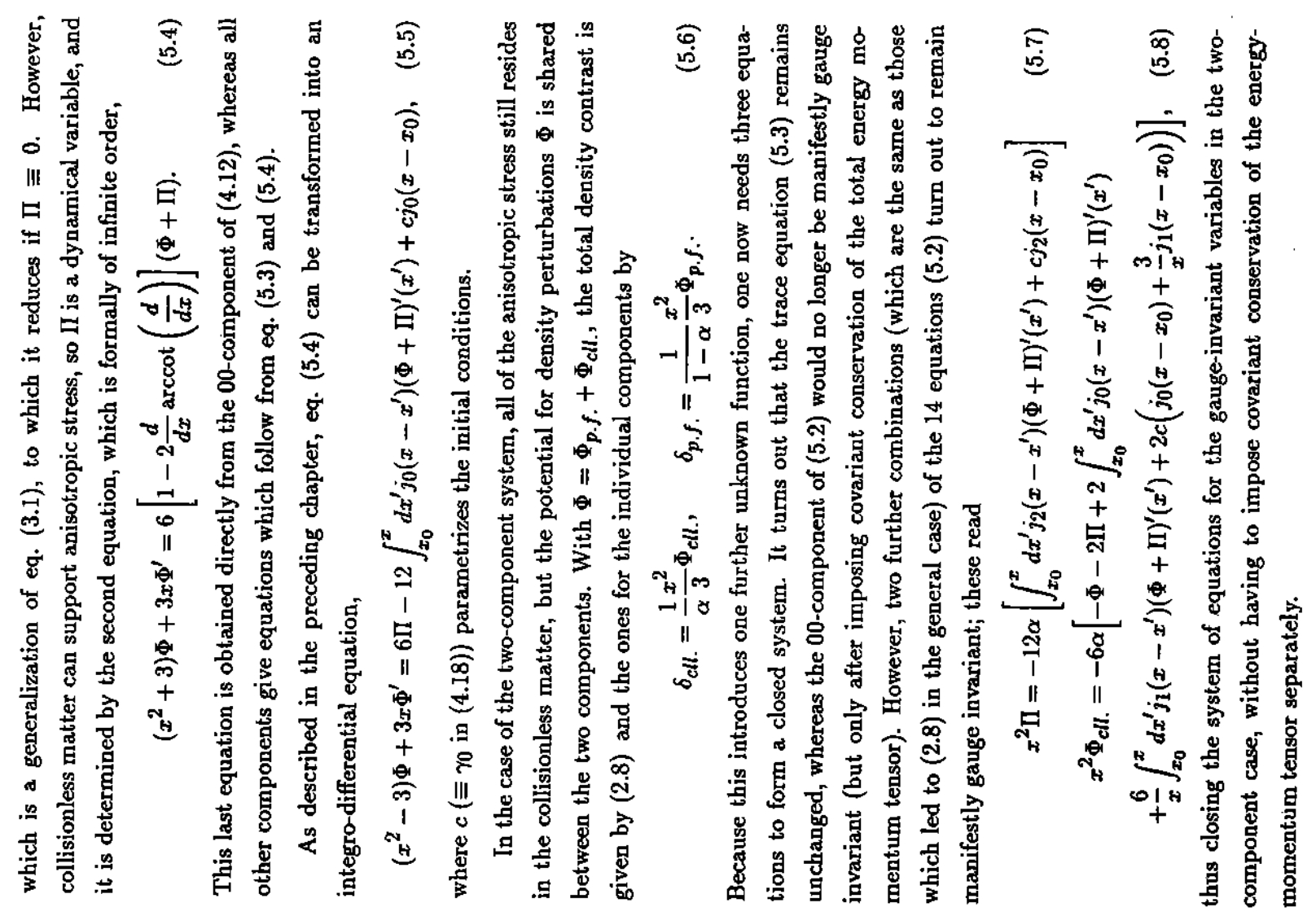

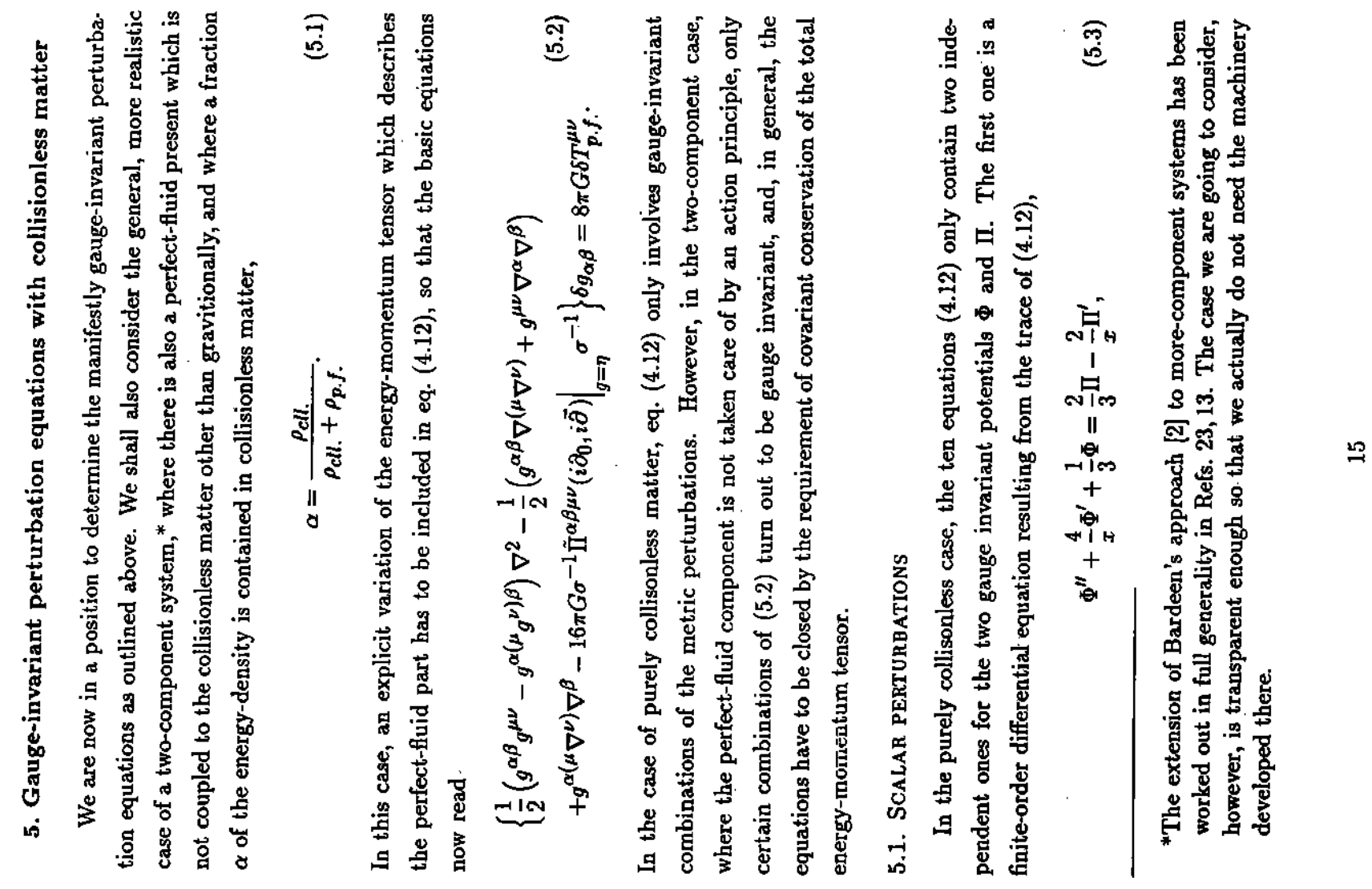



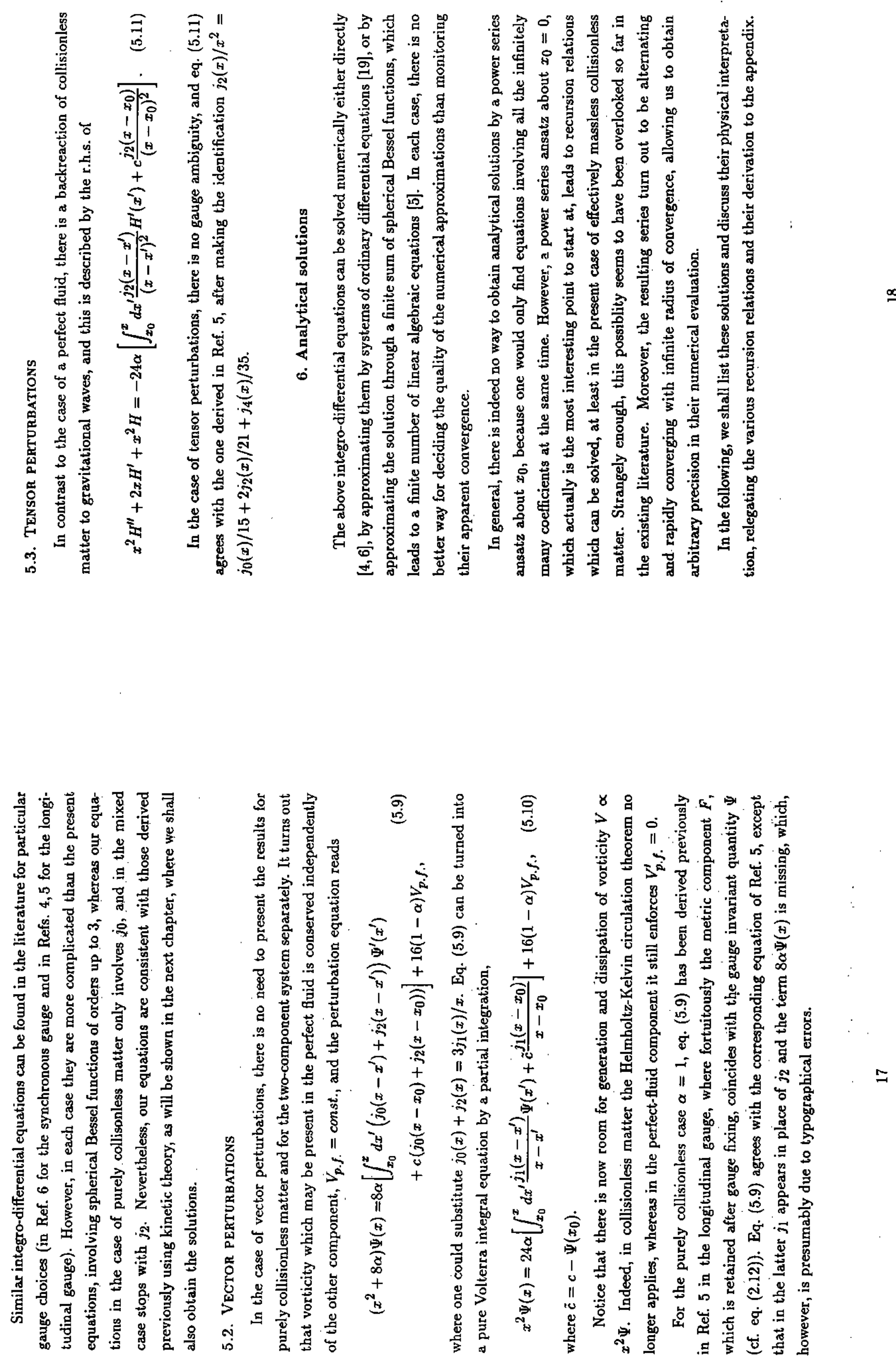

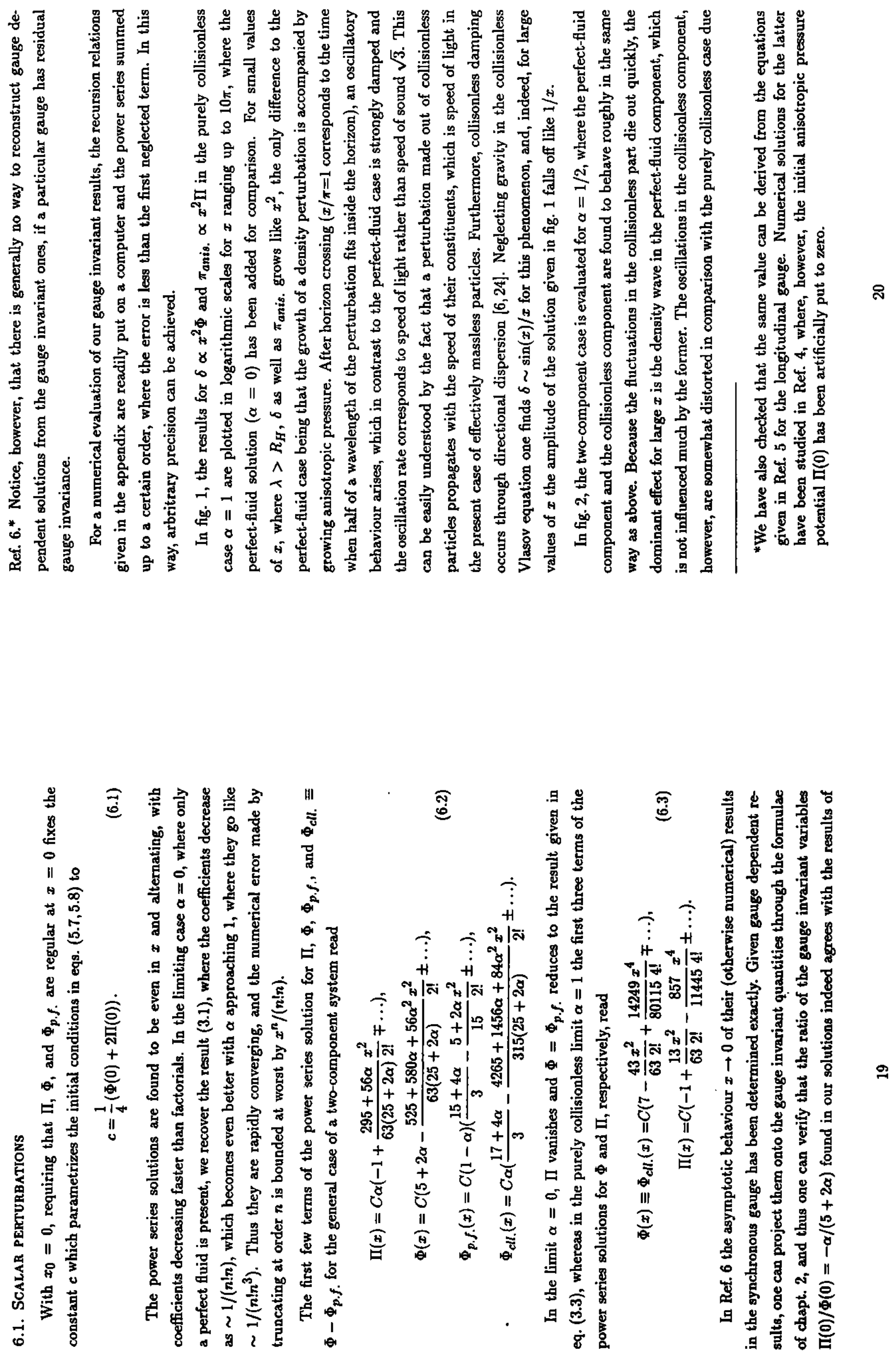

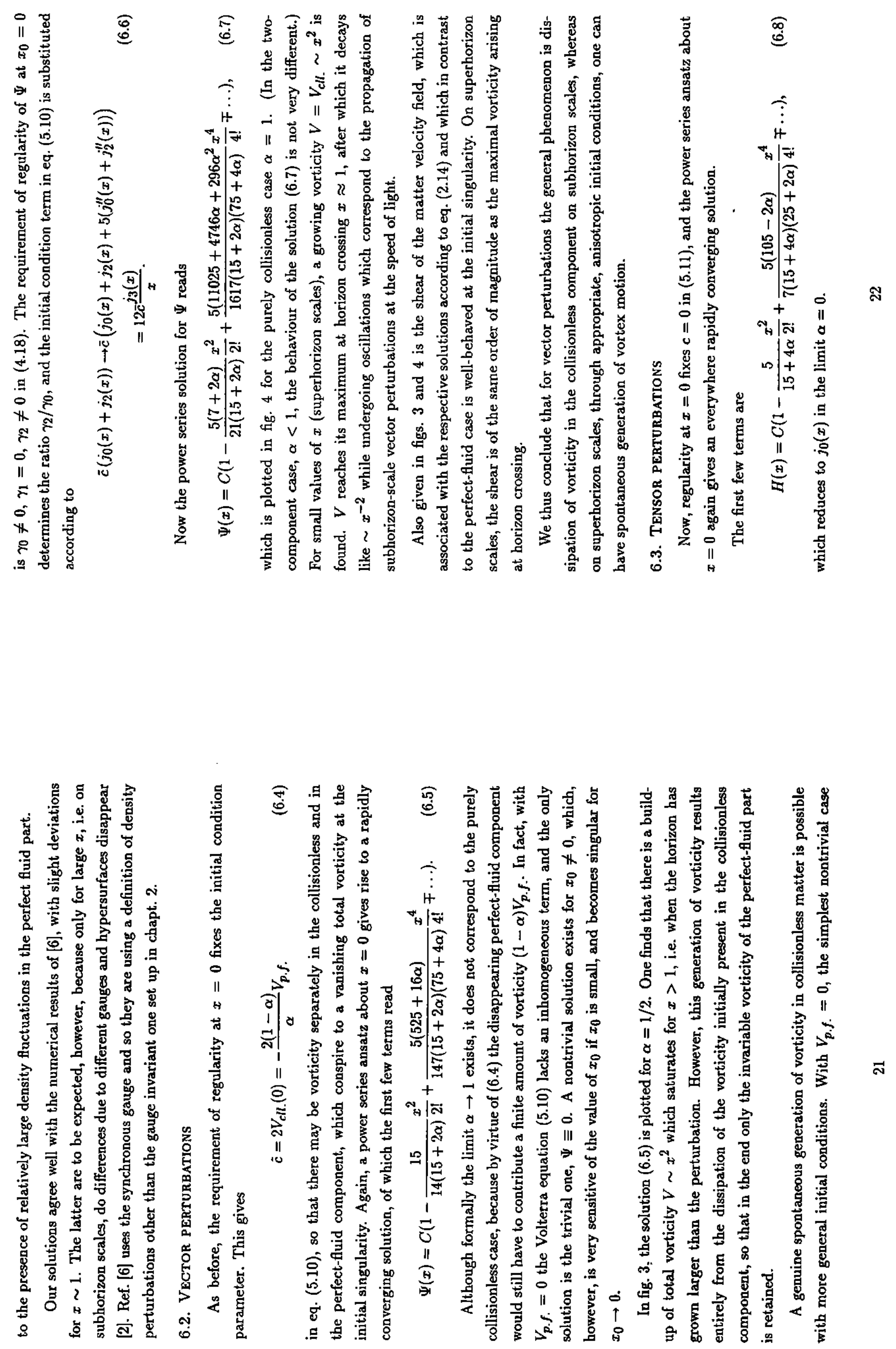


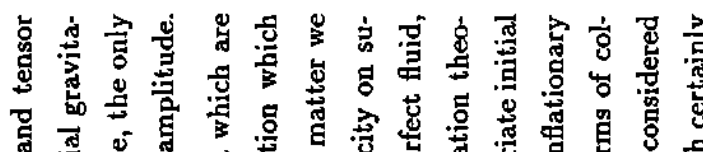

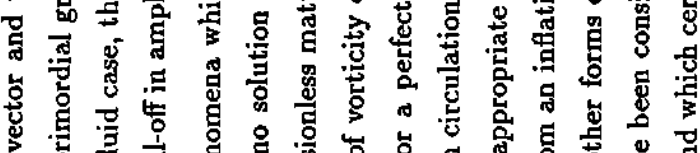

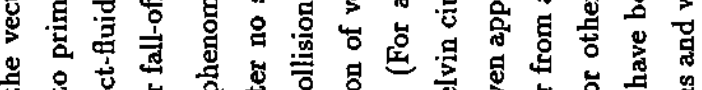

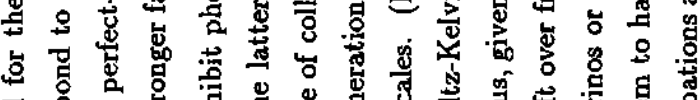

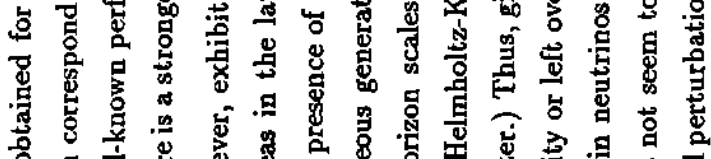

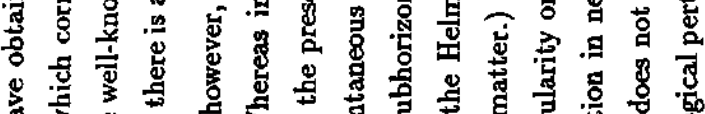

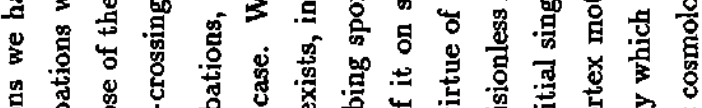

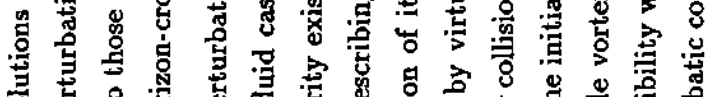

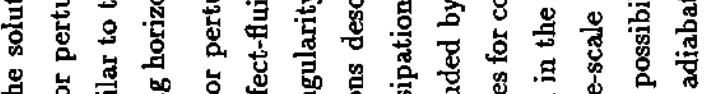

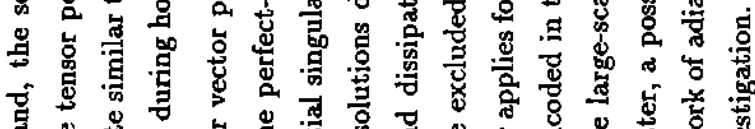

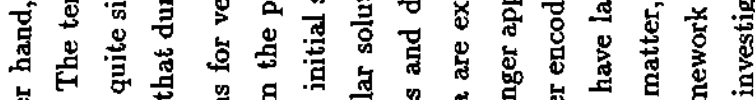

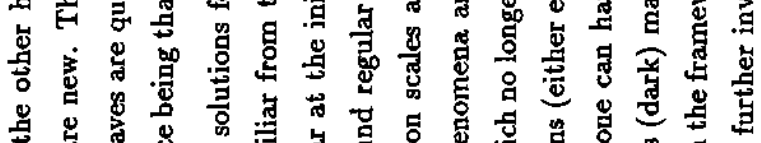

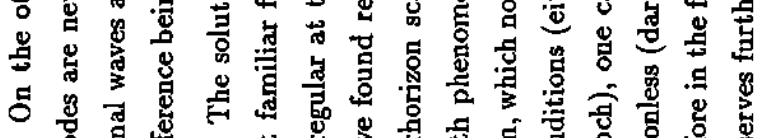

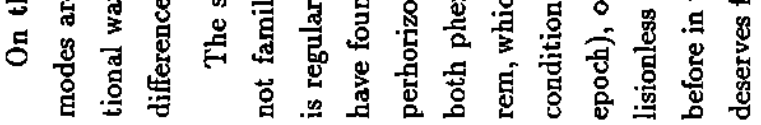

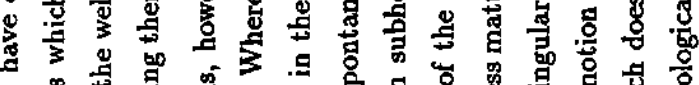

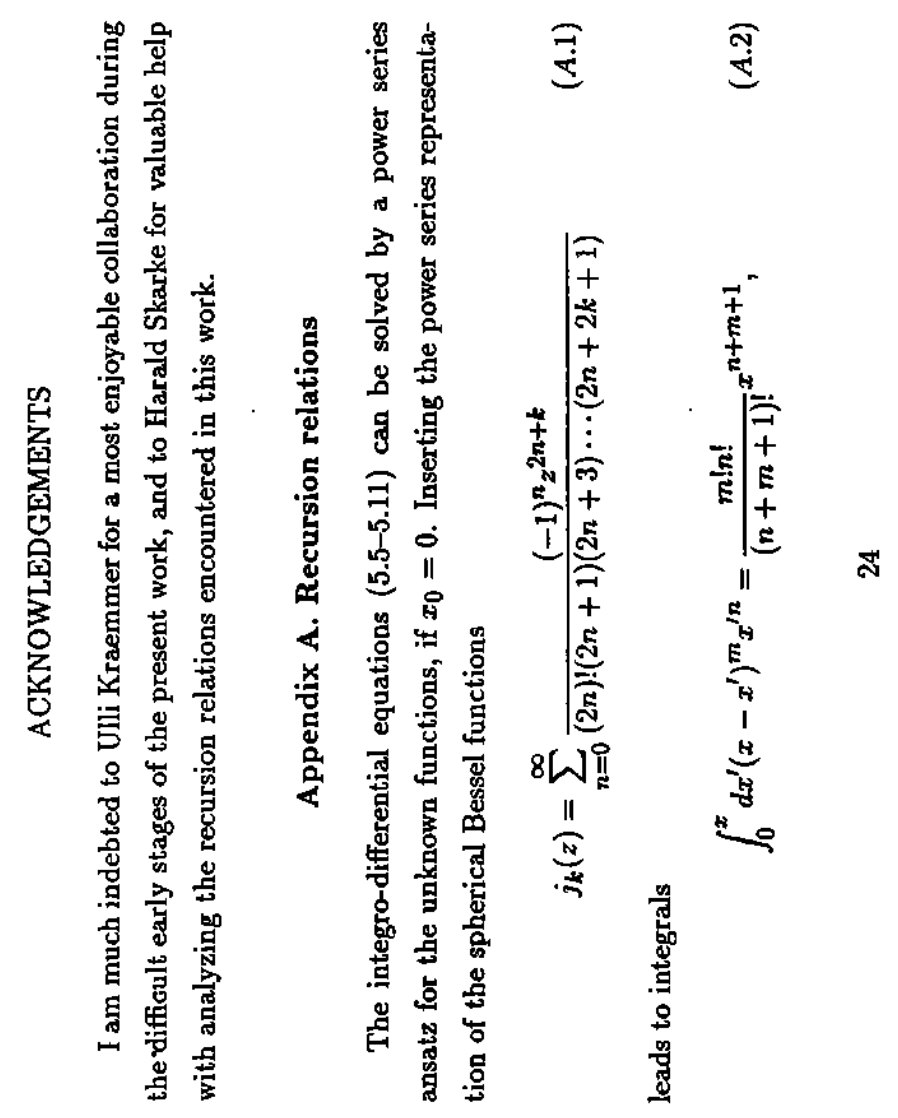

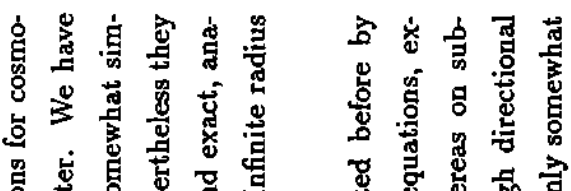
突

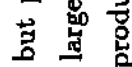
占

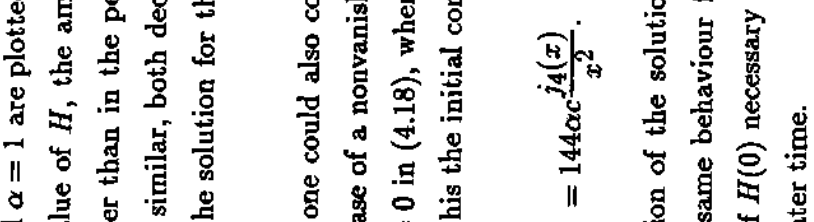

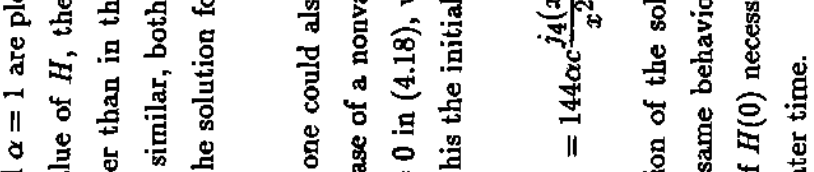

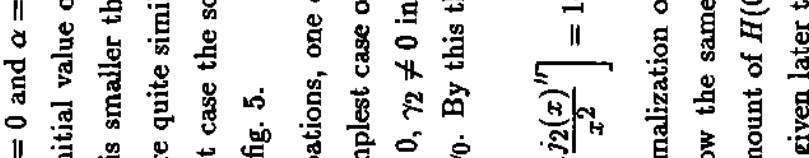

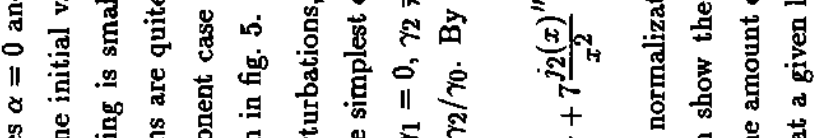
IIII I

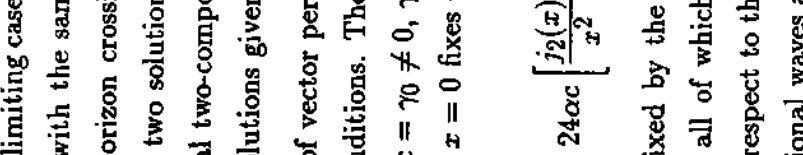

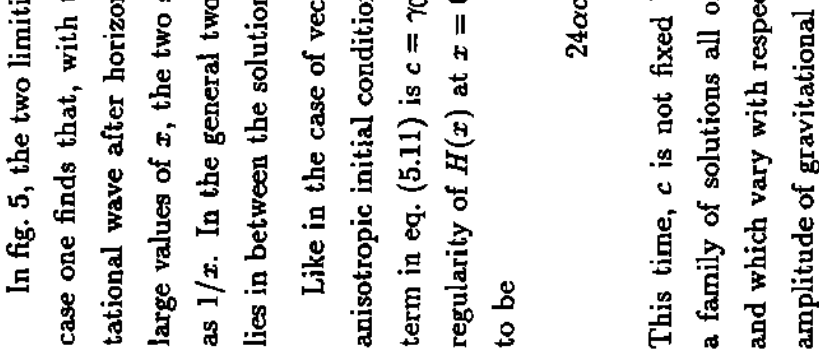

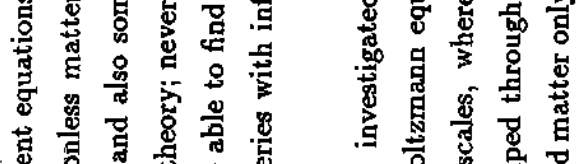

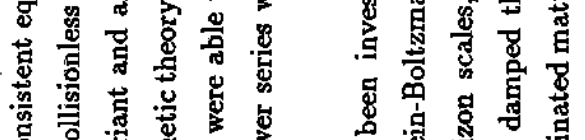
\%

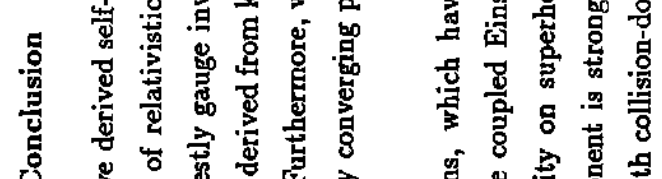

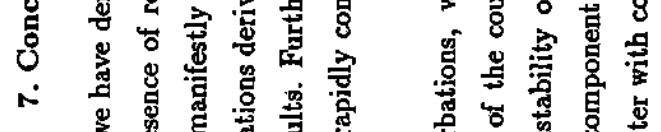

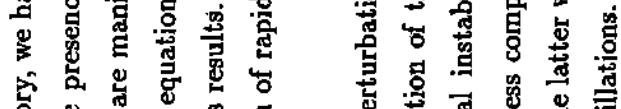

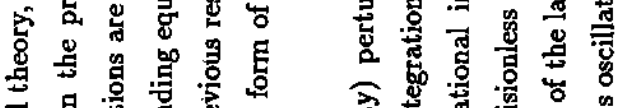

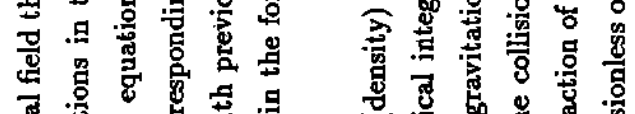

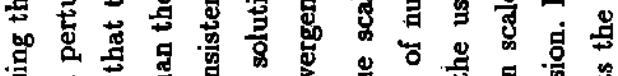

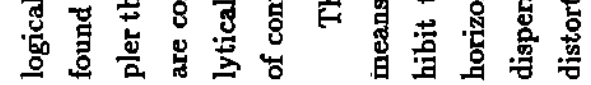

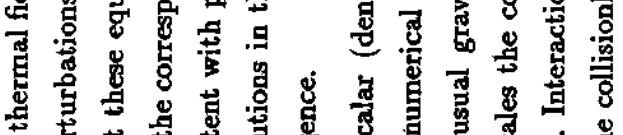

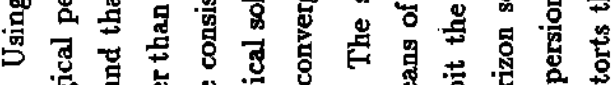




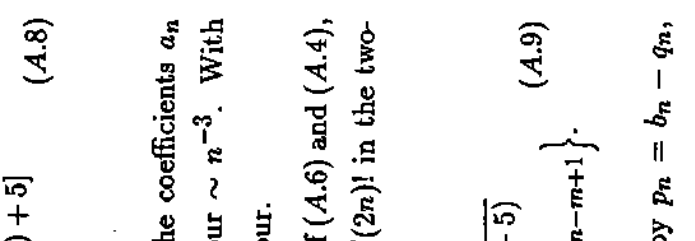

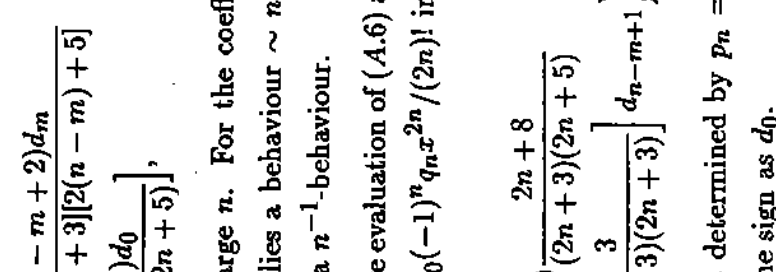

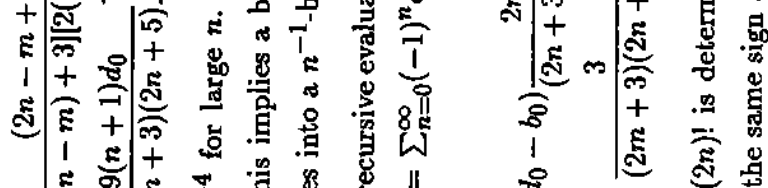

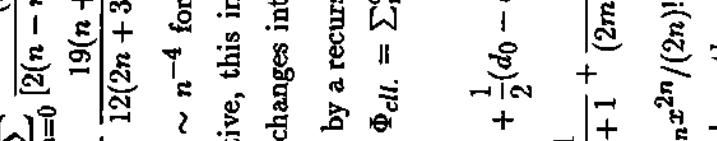

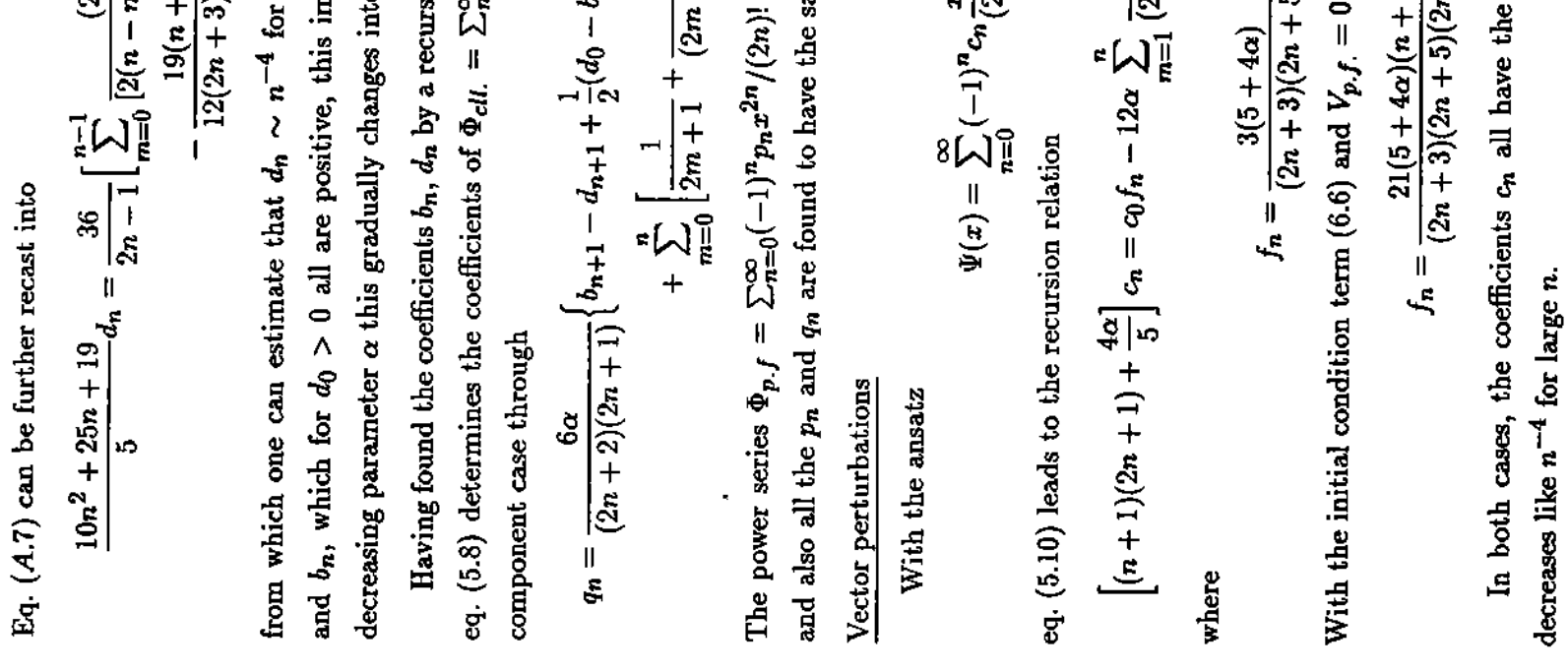

बิ

\&

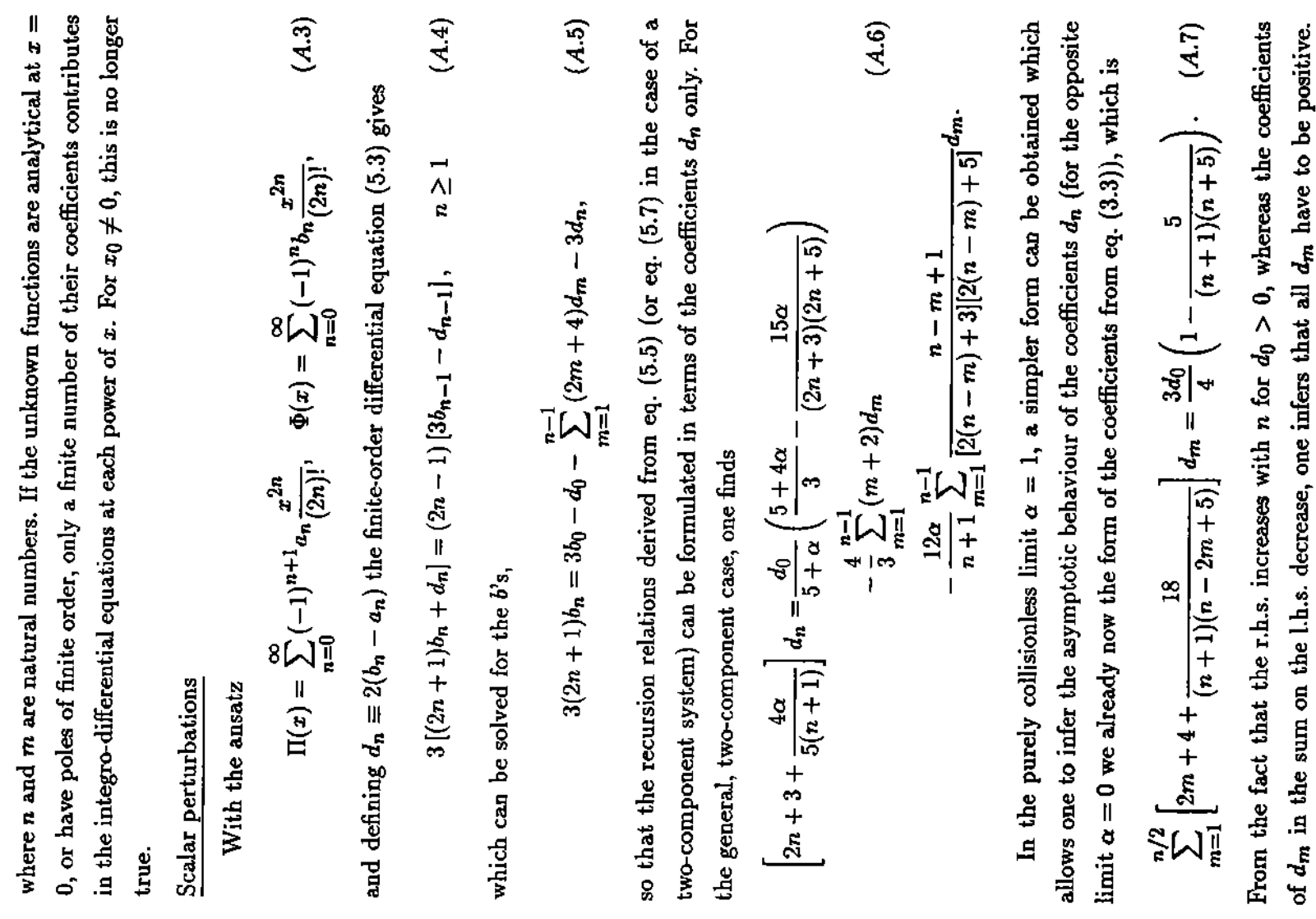

$\stackrel{4}{5}$ 

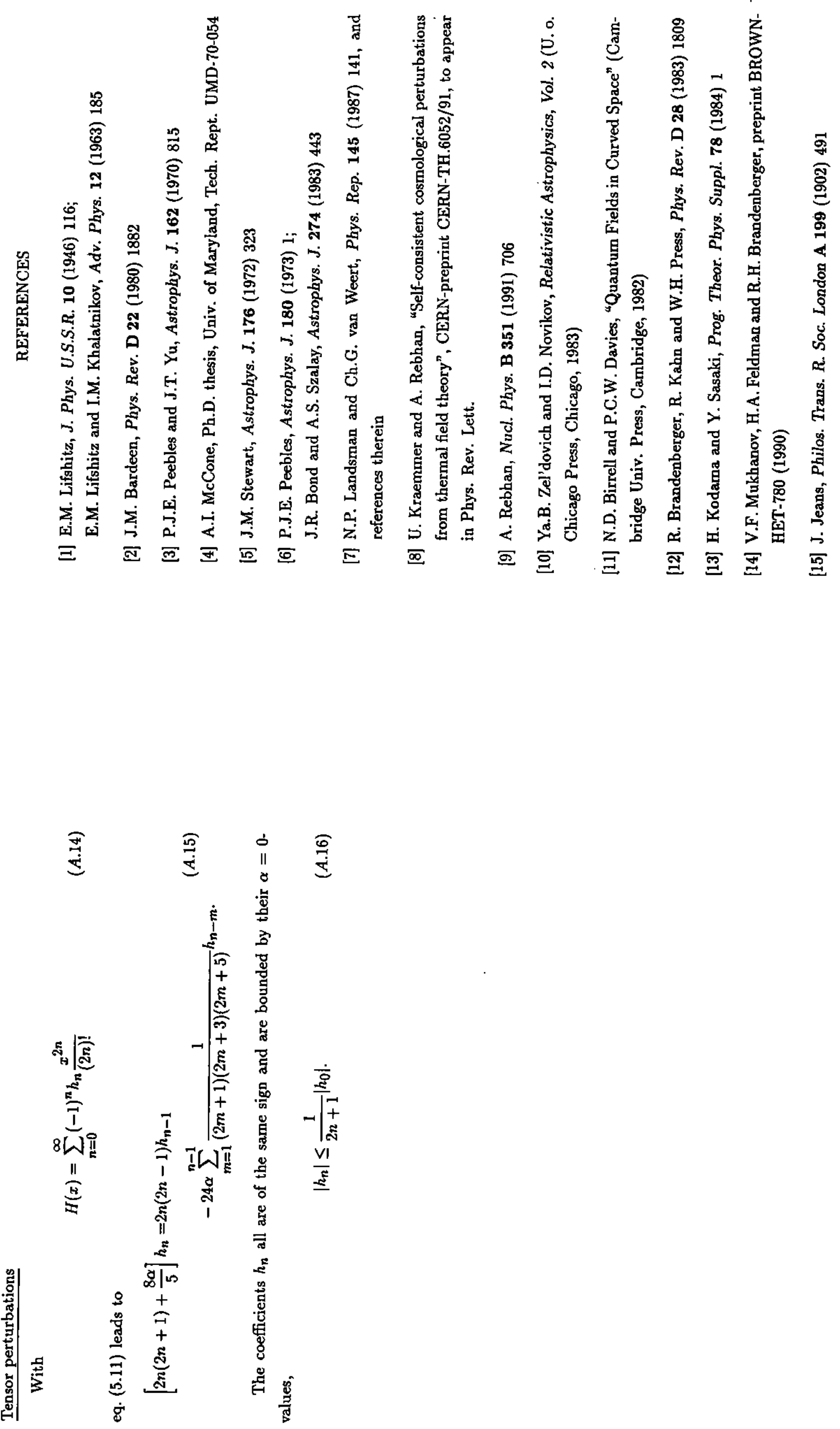

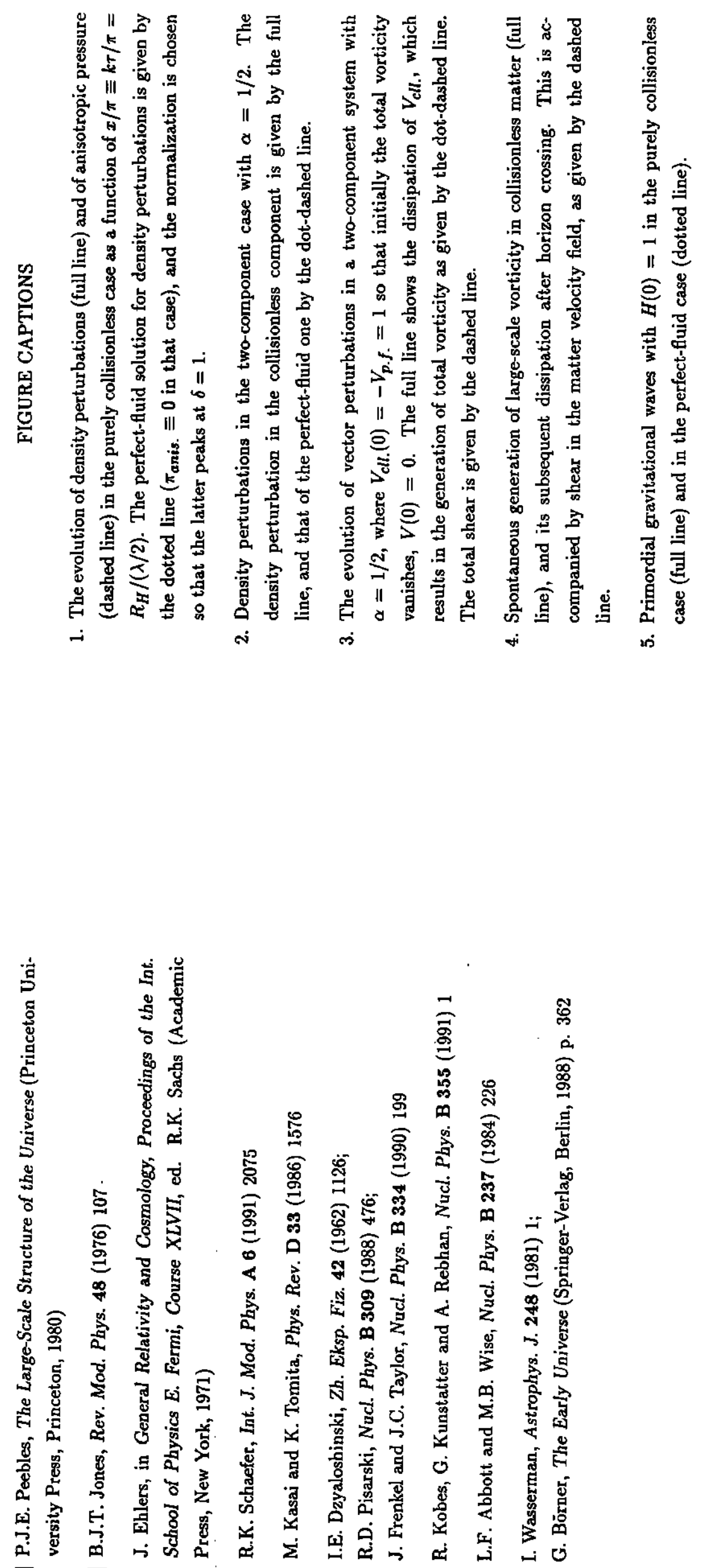


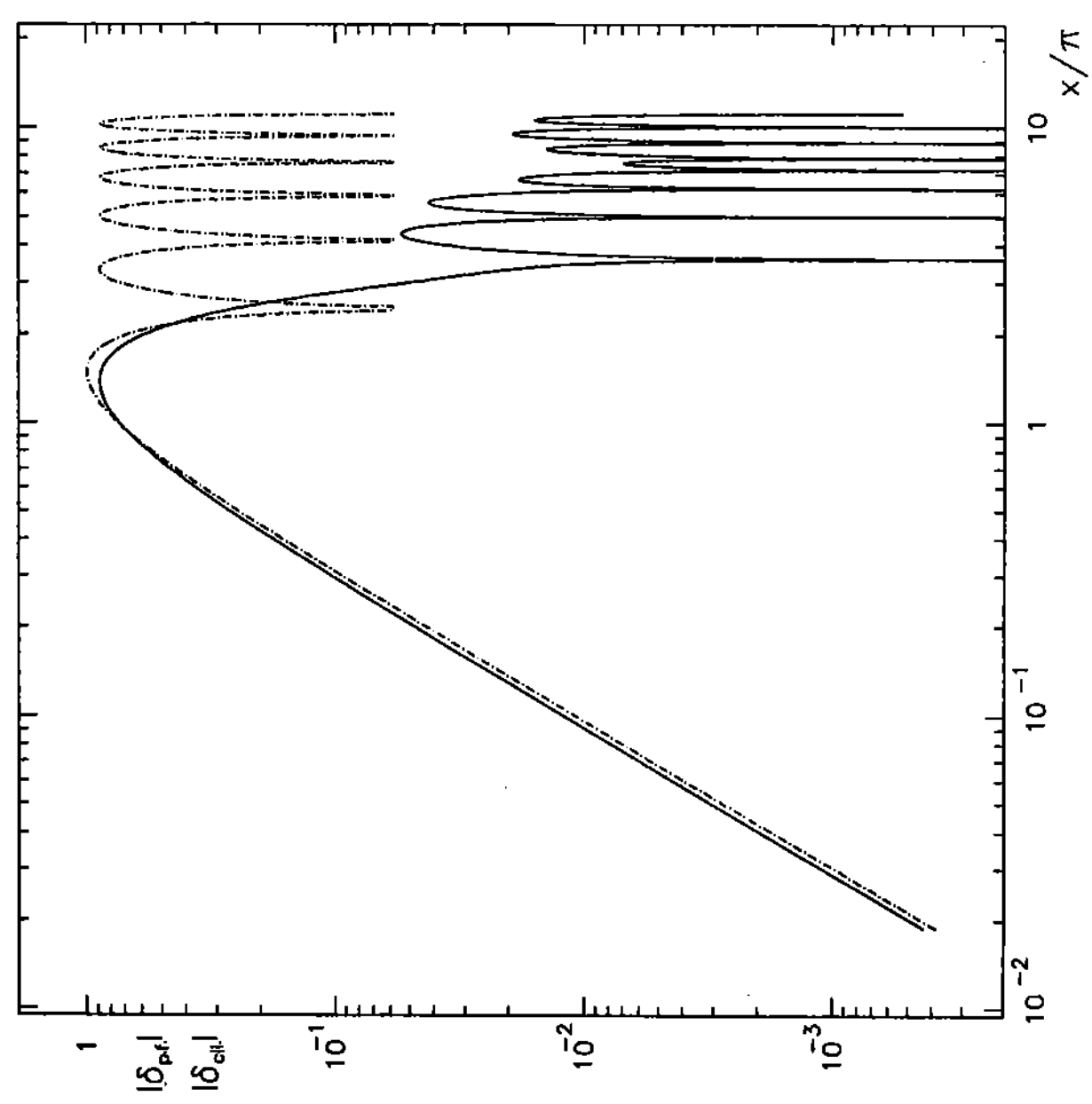

$\underset{1}{\infty}$

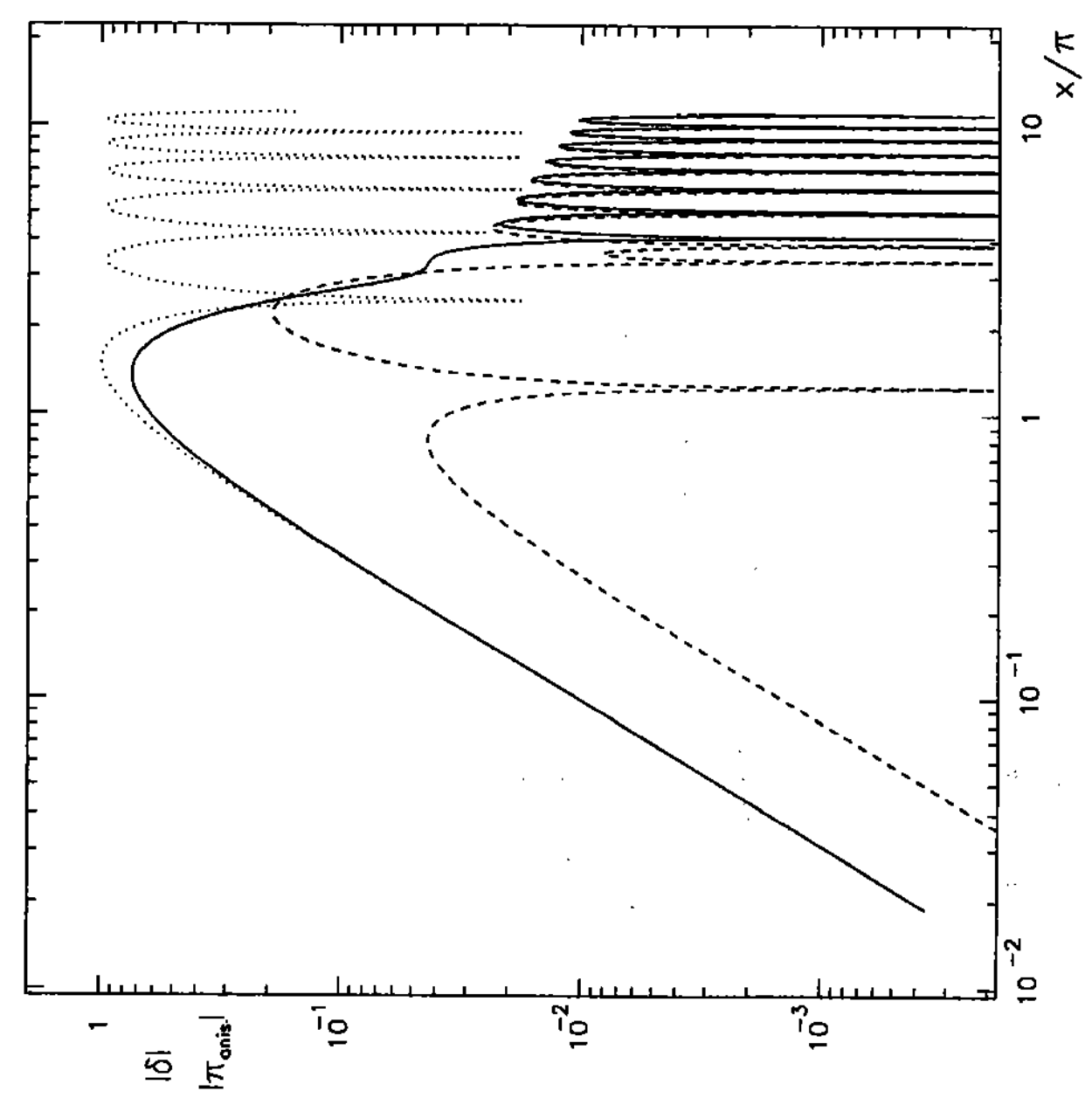



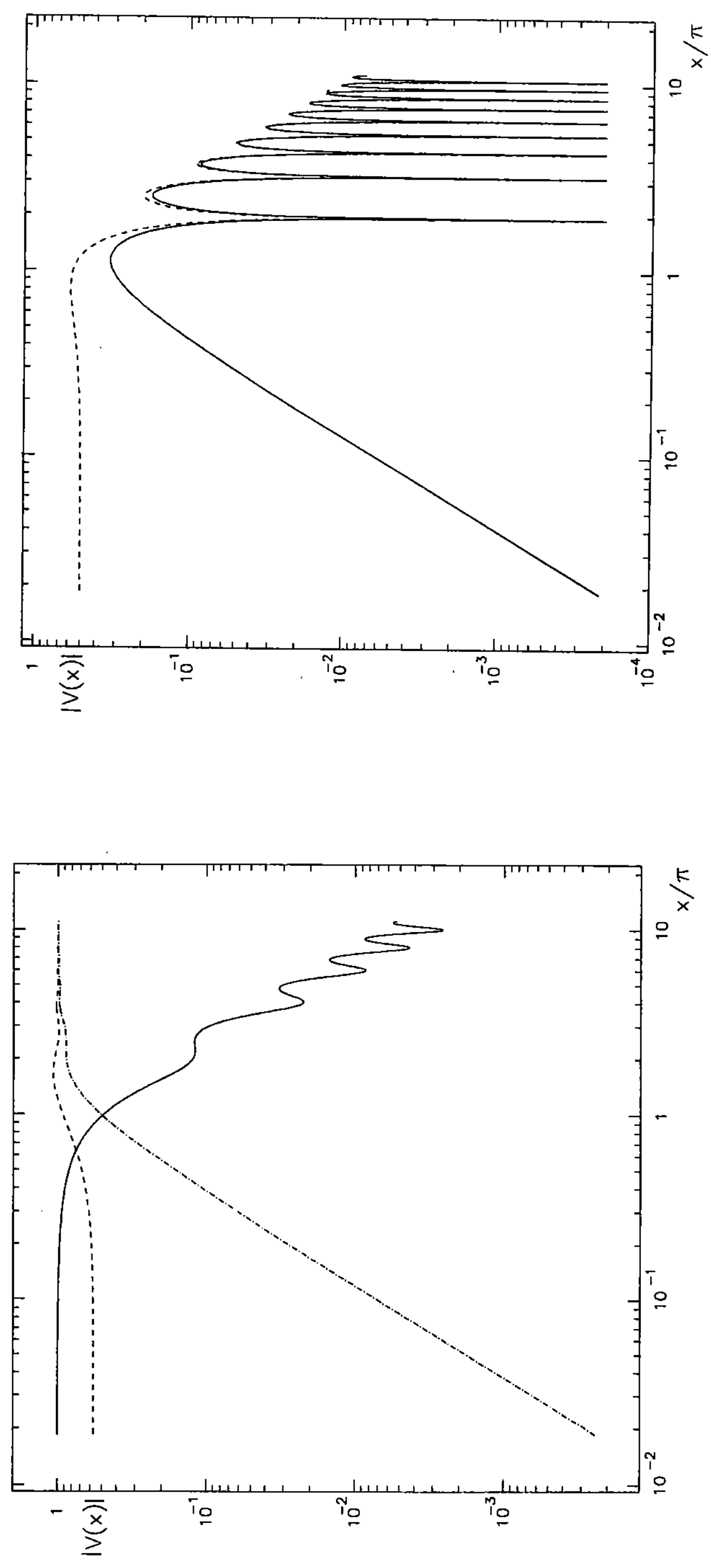
它

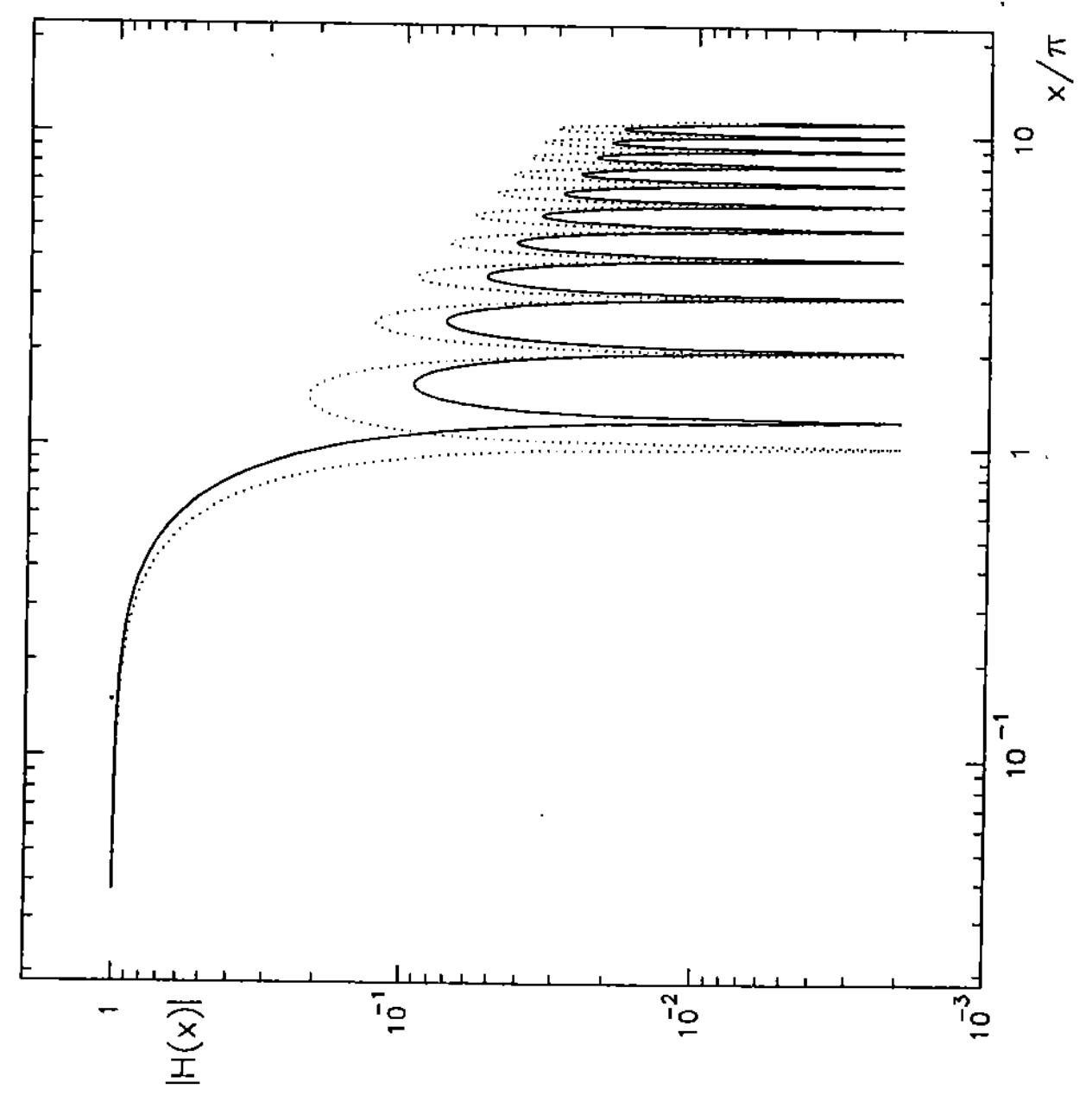

